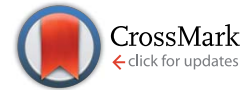

Cite this: RSC Adv., 2015, 5, 73510

Received 15th July 2015

Accepted 24th August 2015

DOI: $10.1039 / c 5 r a 13897 c$

www.rsc.org/advances

\section{Epoxy/graphene nanocomposites - processing and properties: a review}

\author{
Jiacheng Wei, Thuc Vo and Fawad Inam*
}

Graphene has recently attracted significant academic and industrial interest because of its excellent performance in mechanical, electrical and thermal applications. Graphene can significantly improve physical properties of epoxy at extremely small loading when incorporated appropriately. Herein, the structure, preparation and properties of epoxy/graphene nanocomposites are reviewed in general, along with detailed examples drawn from the key scientific literature. The modification of graphene and the utilization of these materials in the fabrication of nanocomposites with different processing methods have been explored. This review has been focused on the processing methods and mechanical, electrical, thermal, and fire retardant properties of the nanocomposites. The synergic effects of graphene and other fillers in epoxy matrix have been summarised as well.

\section{Introduction}

Materials play key roles in every field of technology such as aeronautics, electronics, energy, health, sensors, etc. ${ }^{1}$ It is important to continuously update existing materials and develop new materials with improved properties and multifunctionalities, so they can be exploited for advanced applications. ${ }^{2}$ Compared to traditional composite materials, nanocomposites exhibit extraordinary properties because of the exceptionally high surface to volume ratio of the nanofiller and/

Department of Mechanical and Construction Engineering, Faculty of Engineering and Environment, Northumbria University, Newcastle upon Tyne NE1 8ST, UK. E-mail: fawad.inam@northumbria.ac.uk; Tel: +44 (0)1912273741 or its exceptionally high aspect ratio. ${ }^{3}$ Polymer nanocomposites combine the functionalities of polymer matrices, such as low cost, easy processability, ${ }^{4}$ with the unique features of the inorganic nanoparticles such as high aspect ratio, excellent toughness and strength and other properties like electrical and thermal conductivities. ${ }^{5}$ In the past few years, polymer nanocomposites with enhanced optical, mechanical, electrical, thermal, and fire retardant properties have been developed. ${ }^{6-10}$ However, nanofillers used in these materials have strong tendency to agglomerate which would cause inhomogeneous dispersion of nanofillers in matrices, ${ }^{\mathbf{1 1}}$ and reduction in mechanical and thermal properties of these nanocomposites. The optimum enhancement in the properties of polymer matrices can only be achieved if the nanofillers are uniformly

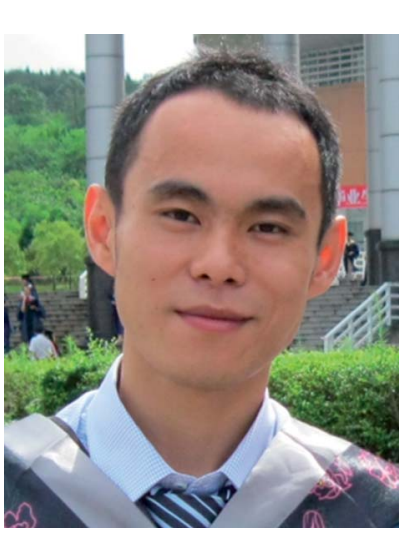

Jiacheng Wei received his Master degree in 2013 from Southwest University of Science and Technology, China. Currently he studies as a PhD candidate in Northumbria University under the supervision of Dr Fawad Inam and Dr Thuc Vo. His focus of research is preparation and development of polymer based materials, especially epoxy/ graphene nanocomposites. Jiacheng is fully funded for his $P h D$ research studentship by the Northumbria University in Newcastle upon Tyne, UK since 2013.

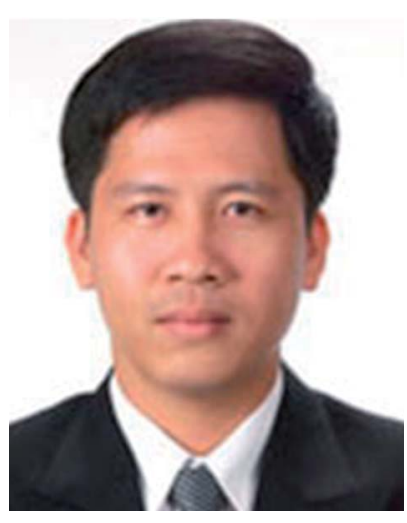

Dr Thuc Vo is a senior lecturer at Northumbria University in Newcastle upon Tyne, UK since 2013. Dr Vo's most recent efforts have been devoted towards the development of refined shear deformation theories to investigate static, vibration and buckling responses of composite structures (laminate, functional graded material and sandwich). Besides, he has published several papers dealing with finite element analysis to understand the behaviour of thin-walled composite structures. He has also implemented a user material subroutine in ABAQUS/Explicit to model blast response of FibreMetal Laminates and novel micro, nano and hybrid composites. 
dispersed. ${ }^{12}$ Attaining the optimum dispersion is one of the main challenges for processing of nanocomposites and therefore it is essential to review the current processing techniques used for preparing nanocomposites.

However, there has been no review article dealing specifically with epoxy/graphene nanocomposites, which is the subject of this paper. Mechanical, electrical, thermal and fire retardant properties of epoxy/graphene nanocomposites have been reviewed; besides that, processing methods and properties of nanomaterials have been correlated. Furthermore, some of the listed points have been highlighted in this paper are:

(1) Summarised a new method of epoxy/graphene nanocomposites preparation - resin impregnation, which impregnating epoxy into a graphene filter cake without pre-mixing.

(2) Summarised the synergic effects of graphene and other fillers in epoxy matrix.

(3) Summarised the reason why thermal stability decreased with the incorporation of graphene.

To the best of our knowledge, those points haven't been seen in other reviews and we believe this review covers most of the important publications relating to the processing and properties of epoxy/graphene nanocomposites to date.

\section{Epoxy}

Discovered in 1936 by Dr Castan of Switzerland and Dr Greenlee of USA, epoxy based materials are used widely because of their superlative mechanical properties, thermal stability, solvent resistance and ease of processing. ${ }^{13}$ Epoxies are one of the most adaptable and widely sold high performance material. ${ }^{14}$ Some of the applications of epoxy and its nanocomposites include aerospace, automotive, marine, sports materials, construction, structures, electrical and electronic systems, biomedical devices, thermal management systems, adhesives, paints and coatings, industrial tooling and other general consumer products. ${ }^{15}$ Because of its versatile nature, epoxy is replacing many

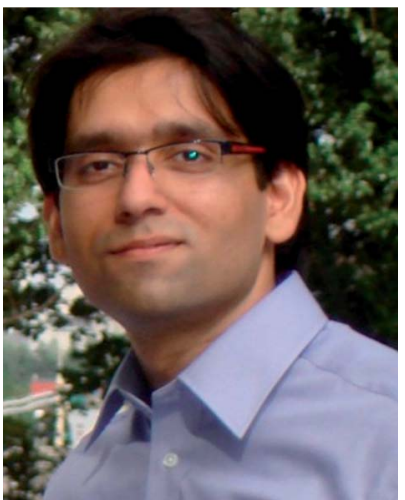

Dr Fawad Inam is the Director of Mechanical Engineering at Northumbria University in Newcastle upon Tyne, UK. His research is on the development of advanced materials including nanomaterials filled with fullerenes. He has worked with numerous aerospace, petroleum, manufacturing, defence and subsea industrial organisations. His expertise includes materials physics and chemistry, processing, characterisation, performance evaluation, applications, materials sustainability and technology commercial exploitation. Dr Inam has produced several high impact publications and authored more than 75 papers in peer-reviewed scientific journals and proceedings to date. He was the founding editor ofjournal "Epoxy" and on the editorial boards of various journals.

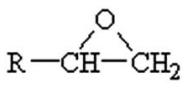

Fig. 1 Molecular structure of epoxide group

conventional materials, e.g. epoxy based materials have already replaced wood in majority of the boats and various sports goods.

Epoxy resins are thermosetting polymers and defined as a molecule containing more than one epoxide groups, as shown in Fig. 1.

The curing process is a chemical reaction in which the epoxide groups in epoxy resin reacts with a hardener (curing agent) to form a highly crosslinked, three-dimensional network. ${ }^{\mathbf{1 6}}$ There are wide varieties of curing agents available for epoxy based materials. Depending on the chemical formulation of the hardeners, epoxy resins can be cured at temperatures range from 5 to $150{ }^{\circ} \mathrm{C}^{17}$ However, epoxy materials with varying engineering applications are often limited by their brittle nature and poor electrical, thermal properties. ${ }^{18}$ A simple solution to overcome this problem is to modify the matrix molecular structure or add compatible fillers. For example, incorporation of inorganic nanofillers has been shown to be a very efficient strategy to increase the performance of the material. ${ }^{19}$

\section{Graphene}

\subsection{History and properties}

Since the historical observation of single layer graphene by Andre Geim and Kostya Novoselov in 2004, ${ }^{20}$ this atomically thin carbon sheet has received ever-increasing attention and become a rapidly rising star on the horizon of materials science. ${ }^{21}$ For example, recently the European Commission has financed a 10 year research initiative, the European Graphene Flagship, which provides 1 billion Euro in funding and involves more than 140 academic and commercial institutions in 23 countries. $^{22}$

Graphene exhibits many specific and useful properties such as large surface area $\left(2630 \mathrm{~m}^{2} \mathrm{~g}^{-1}\right),{ }^{23}$ excellent thermal conductivity (5000 $\left.\mathrm{W} \mathrm{m}^{-1} \mathrm{~s}^{-1}\right),{ }^{24}$ very high Young's modulus (1 $\mathrm{TPa}){ }^{25}$ high value of white light transmittance as to $97.7 \%,{ }^{26}$ exceptionally high room-temperature electron mobility of $2.5 \times$ $10^{5} \mathrm{~cm}^{2} \mathrm{~V}^{-1} \mathrm{~s}^{-1} .^{27}$ These fascinating properties have attracted extensive research interest in recent years with ever-increasing scientific and technological impetus.

For example, as a conductive nanomaterial, graphene can be used for printed electronics beyond conventional silicon based technologies. ${ }^{28}$ For energy storage, Yang et $a .^{29}$ prepared a supercapacitor with a capacitance of 200-300 $\mathrm{F} \mathrm{g}^{-1}$. Kim et al. $^{30}$ used graphene as a transparent electrode and fabricated an organic photovoltaic devices; Prasai et al. ${ }^{31}$ incorporated graphene into organic coatings significantly enhanced its corrosion resistance. Therefore, it can be concluded that significant achievements have been made at the cross-section of nanotechnology and various applications by employing the specific properties of graphene. ${ }^{32}$ 


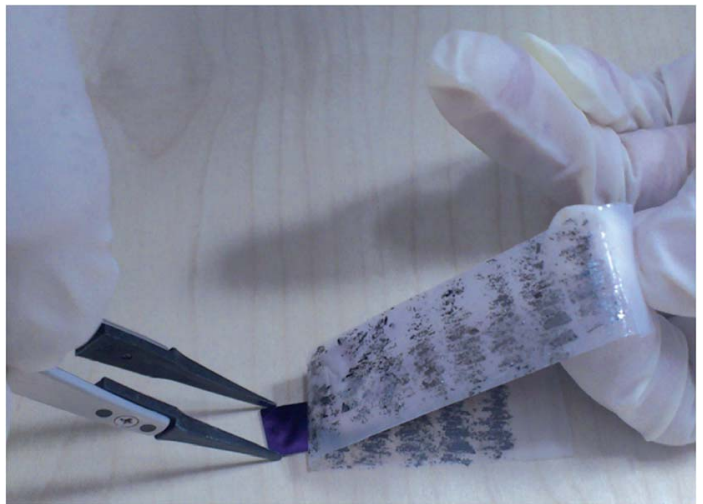

Fig. 2 Scotch tape method of graphene synthesis from graphite block. ${ }^{39}$ Reproduced with permission from ref. 39.

\subsection{Fabrication}

Efforts to exfoliate graphite down to its ultimate constituent can be dated back to $1960 \mathrm{~s}$. Fernandez et $a .^{33}$ extracted millimetresized graphene sheets (as thin as $5 \mathrm{~nm}$, about 15 layers) from graphite crystals by micromechanical exfoliation for the very first time. However, it was not until 2004, Andre Geim and Kostya Novoselov $^{20}$ isolated individual graphene layers by repeatedly cleaving a graphite crystal with a scotch tape to its limit. This led to the creation of a wonder two dimensional (2D) material, marking the onset of successful fabrication of graphene.

Micromechanical exfoliation, the top-down method, is a simple peeling process as shown in Fig. 2. Similarly, ultrasonication also produce thin graphene sheets. ${ }^{34}$ Currently, exfoliation of bulk graphite is the most commonly used method for the mass production of small graphene sheets. ${ }^{35}$ This can be through direct exfoliation in a liquid, with or without the use of surfactant, ${ }^{36}$ or in the solid state by edge functionalization, ${ }^{37}$ or by first inserting a chemical species between the graphene layers in graphite to weaken their interaction and then followed by thorough exfoliation. ${ }^{38}$

Bottom-up approaches have also been developed such as Chemical Vapour Deposition (CVD). ${ }^{40}$ In a typical CVD process, a substrate is exposed to volatile precursors in a reaction chamber and the precursors react and/or decompose on the substrate surface to produce the desired deposit. ${ }^{41}$ For graphene production, silicon or a transition metal often serves as the substrate. The CVD chamber is vacuumed and heated in the presence of catalyst and hydrocarbon gases are induced and decomposed. This process deposits a spread of carbon atoms onto the surface of the substrate, thus forming the graphene layers. ${ }^{42}$

Another advanced method is the chemical reduction of exfoliated graphene oxide, which is an economical and very practical approach to synthesise graphene. ${ }^{43}$ This process takes the advantage of $\pi-\pi$ interactions of graphene oxide and other molecules such as hydrazine, one of the most effective reductive agents, which can effectively return graphene oxide to its original state. ${ }^{\mathbf{4 4}}$ This method maintains graphene's electrical conductivity, flatness and optical properties, but it's not as same as pristine graphene and still contains some significant oxygen groups and a few irreversible lattice defects. ${ }^{45}$

There are a number of other growth methods, some of these methods have certain advantages and should be investigated further, such as arc discharge method, ${ }^{\mathbf{4 6}}$ template route method, ${ }^{47}$ electrochemical synthesis of graphene ${ }^{\mathbf{4 8}}$ and total organic synthesis of graphene. ${ }^{\mathbf{4 9}}$ Many studies have been directed towards developing techniques to create single layer graphene, however, to date, scalable production of single layer graphene is still at exploration stage and there is no mature method to produce good quality graphene in mass quantity. ${ }^{50} \mathrm{In}$ general, mechanical exfoliation, CVD, chemical reduction, epitaxial growth of graphene are among the most notable techniques in graphene production. ${ }^{51}$

\subsection{Graphene oxide (GO) and functionalization of graphene}

3.3.1 GO. GO is obtained from the exhaustive oxidation and exfoliation of graphite, and contains a range of oxygen functional groups with specific chemistry. ${ }^{52}$ It is generally produced by the treatment of graphite using strong mineral acids and oxidizing agents, typically via treatment with $\mathrm{KMnO}_{4}$ and $\mathrm{H}_{2} \mathrm{SO}_{4}$ as in the Hummers ${ }^{53}$ method, or $\mathrm{KClO}_{3}$ (or $\mathrm{NaClO}_{3}$ ) and $\mathrm{HNO}_{3}$ as in the Staudenmaier ${ }^{54}$ or Brodie ${ }^{55}$ methods, or some variation of these methods. There is no unambiguous model to describe the exact structure of GO because there is no single definitive analytical technique available to characterize this material. However, it is generally accepted that the carboxylic groups are mainly located at the edge, while the rest of functional groups (hydroxyl, epoxide, etc.) are present in highest concentration in the basal planes of the graphene layers. ${ }^{56}$ Fig. 3 shows a proposed structure of graphene oxide that is supported by solid-state nuclear magnetic resonance (SSNMR) experiments on ${ }^{13} \mathrm{C}$-labeled GO.

The oxygen functional groups on GO surface are polar and renders GO hydrophilic. GO can be dispersed in many solvents, and particularly well in water. ${ }^{58}$ In addition, currently the most promising methods for large scale production of graphene are based on exfoliation and reduction of graphene oxide. ${ }^{59}$

3.3.2 Functionalization of graphene. Pristine graphene is unsuitable for intercalation with large species, such as polymer chains, because graphene has a pronounced tendency to agglomerate in polymer matrices. ${ }^{\mathbf{6 0}}$ As observed for other

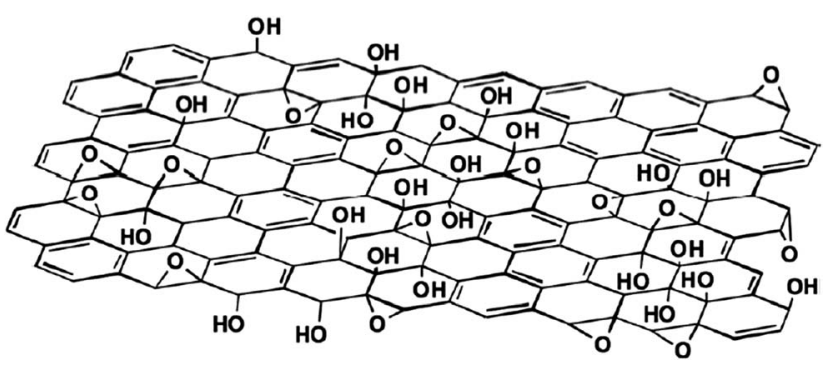

Fig. 3 A proposed schematic (Lerf-Klinowski model) of graphene oxide structure. ${ }^{57}$ Reproduced with permission from ref. 57. 
nanofillers, the maximum improvements in final properties can be achieved when the filler is homogeneously dispersed in the matrices because the external load is efficiently transferred through strong polymer/filler interfacial interactions. ${ }^{61}$ Thus, dispersion and strong interaction between graphene and matrices play important role for the performance of graphene nanocomposites. ${ }^{62}$

The chemical functionalization of graphene is of significant interest because it can not only improve the solubility and processability but can also enhance the interactions with organic polymers. ${ }^{63-66}$ The functional groups attached to graphene can be small molecules ${ }^{67}$ or long polymer chains, ${ }^{68}$ for which various functionalization approaches have been researched such as covalent and non-covalent functionalization of graphene. ${ }^{69}$

Covalent functionalization is based on the covalent linkage between graphene and other functional groups. ${ }^{70}$ The structural alteration can take place at the end of the sheets and/or on the surface. ${ }^{71}$ Covalent functionalization is associated with rehybridization of one or more $\mathrm{sp}^{2}$ carbon atoms of the carbon network into the $\mathrm{sp}^{3}$ configuration accompanied by simultaneous loss of electronic conjugation. ${ }^{72}$ The covalent modification of graphene can be achieved in four different ways: nucleophilic substitution, electrophilic addition, condensation, and addition. ${ }^{73}$ By conducting an epoxide ring-opening reaction, Yang et $a l .{ }^{74}$ covalently grafted 1-(3-aminopropyl)-3methylimidazolium bromide onto the surface of graphene sheets. The modified graphene showed enhanced solubility in water, $N, N$-dimethylformamide (DMF) and dimethyl sulfoxide (DMSO) at various concentrations and formed long-term stable and homogeneous dispersions.

Non-covalent functionalization helps in networking or connecting the molecules without actually forming chemical bonds. However, this process requires the physical adsorption of suitable molecules on the graphene surface. ${ }^{75}$ This can be achieved by wrapping molecules around the graphene by forming van der Waals bonds between functional groups and graphene, such as $\pi-\pi$ interactions, electrostatic attraction, adsorption of surfactants and polymer wrapping. ${ }^{76-79}$ For example, Song et $a .^{\mathbf{8 0}}$ prepared epoxy/graphene nanocomposites with improved mechanical properties and thermal conductivities by non-covalent functionalization of graphene. The modified graphene showed good dispersibility in acetone, DMF, ethanol, pyridine, methanol, tetrahydrofuran (THF) and water, but only short-term stability in iso-propyl alcohol (IPA), dichlorobenzene (DCB), chloroform, dichloromethane and chlorobenzene. This short-term stability is attributed to the surface functional group 1-pyrenebutyric acid, which is not compatible with these solvents.

\section{Epoxy/graphene nanocomposites}

Epoxy and its composites are versatile materials for plenty of industrial fields like electrical and thermal applications, highperformance nanocomposites in automobiles and aerospace applications but these composites have some limitations as well. As a young rising carbon allotrope, graphene showed a new

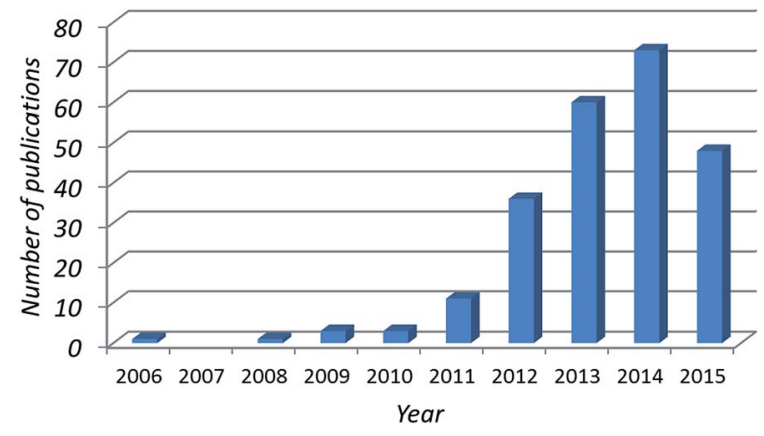

Fig. 4 Number of publications returned using "graphene epoxy" as keywords searched "in title" in Web of Science (by 30/06/2015).

path to overcome these limitations. The exploration of property enhancement of epoxy/graphene nanocomposites is rapidly advancing as evident in Fig. 4, which shows the dramatic increase in epoxy/graphene nanocomposites research in recent years.

\subsection{Processing methods}

Obtaining a good distribution of the graphene-reinforcement is one of the greatest challenges in the preparation of epoxy/ graphene nanocomposites. A well dispersed state ensures availability of maximum surface area of filler, which will affect the neighbouring polymer chains and, consequently, the properties of the whole nanocomposite.$^{81}$ For epoxy or any other matrices, dispersion significantly depends on the processing techniques. Significant research has been carried out on the manufacturing techniques for achieving a homogeneous and well-dispersed system..$^{\mathbf{8 2}-88}$ The commonly used methods for epoxy/graphene nanocomposites are solution mixing, and recently, a newly emerged method as epoxy impregnation and will be discussed here.

4.1.1 Solvent processing. The simplest and most widely used method for processing epoxy/graphene nanocomposites is to take advantage of the presence of functional groups attached on the graphene surface which enables the direct dispersion of graphene in water and many organic solvents. This contributes to strong physical or chemical interaction between the functionalized graphene and polymeric matrices. ${ }^{89}$ A number of studies explain how the surface modification of graphene has been done by adding various functional groups such as amine, ${ }^{90}$ organic phosphate, ${ }^{91}$ silane,,$^{92}$ plasma ${ }^{93}$ etc.

Functionalized graphene is normally dispersed in a suitable solvent by, for example, bath sonication, then mixed with epoxy resin, and then solvent is evaporated in a controlled condition. ${ }^{94}$ The guiding principle is to select solvents compatible with the functional groups on the surface of graphene, and the functional group should be compatible with the epoxy resin as well. ${ }^{95}$ To achieve better dispersion of functionalized graphene, many solvents have been investigated. Rafiee et al. ${ }^{96}$ prepared epoxy/graphene nanocomposites by dispersing graphene platelets in acetone by tip sonication, mixed graphene/acetone solution with epoxy resin and finally acetone was then 


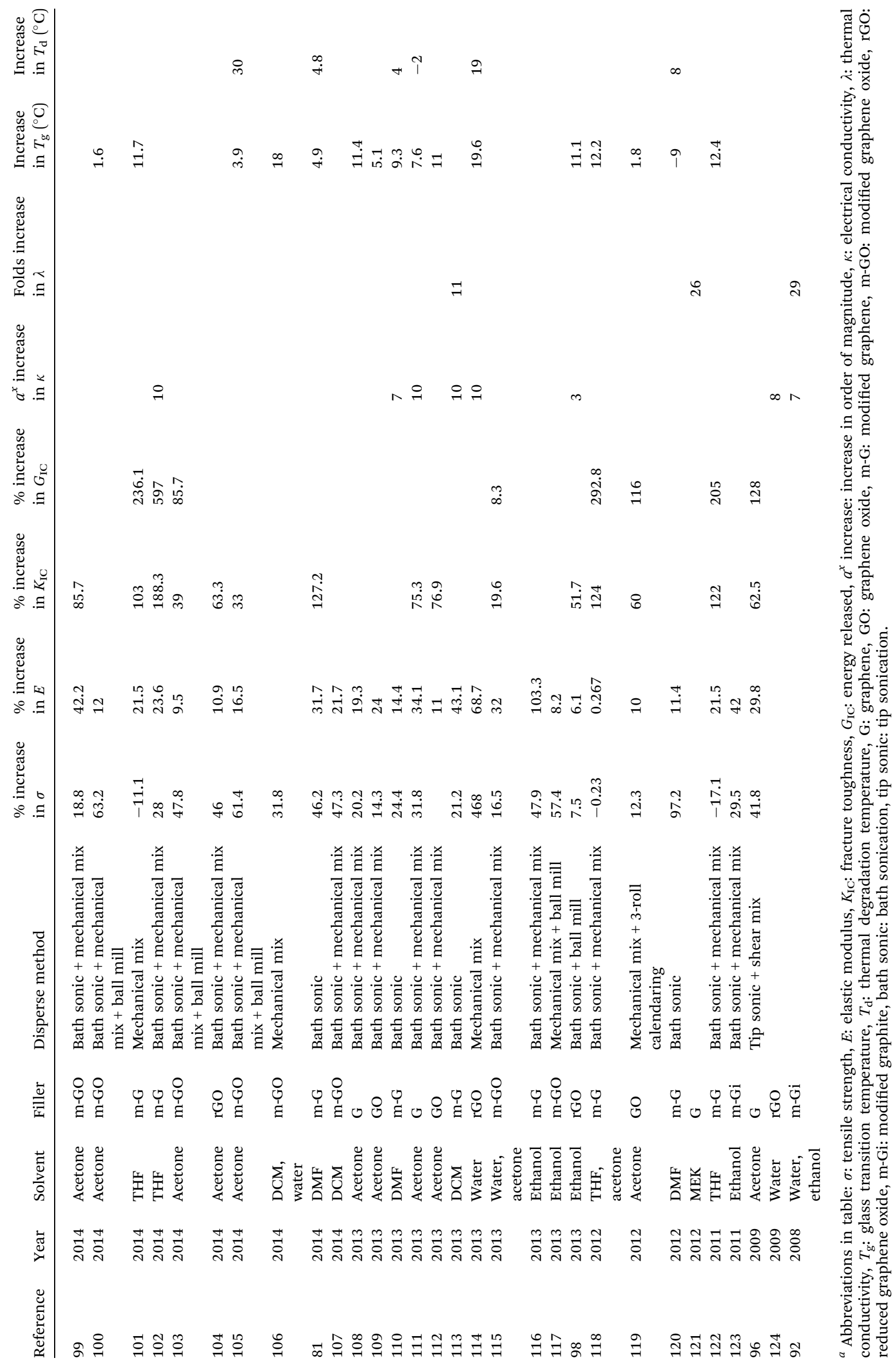


removed by heating the mixture to $70{ }^{\circ} \mathrm{C}$. The prepared nanocomposites showed enhanced mechanical properties and resistance to fatigue crack growth at low graphene concentration (0.1 wt\%). Fang et al. ${ }^{97}$ dispersed graphene in DMF under bath sonication and modified graphene with amine, which provided a mechanical adhesion at the graphene-epoxy interface. The nanocomposites showed improved load transfer efficiency between graphene nanosheets and the matrix, accompanied by the enhanced dissipation capacity of nanocomposites for strain energy during fracture. Tang et al. ${ }^{98}$ investigated the influence of reduced graphene oxide (rGO) dispersion on the mechanical properties of epoxy resin. They found that with the assistance of ball milling in ethanol solution, the blends showed higher dispersibility, which resulted in higher strength and fracture toughness of epoxy resin as well as improved glass transition temperature $\left(T_{\mathrm{g}}\right)$ and electrical conductivity. In addition, they also found that the highly dispersed rGO resulted in much more tortuous and fine riverlike structures on the fractured surface. This consumes more fracture energy in comparison with the poorly dispersed rGO, or in other words improves the fracture toughness of the material. Chatterjee et al. ${ }^{90}$ investigated the reinforcements of mechanical and thermal properties of a functionalized graphene filled epoxy nanocomposites. The amine functionalized expanded graphene nanoplatelets (GNP) were dispersed within epoxy resins using high-pressure processor followed by three roll milling in the solvent of acetone. The resulting nanocomposite exhibited significant improvements in mechanical properties and thermal conductivity indicating a favourable interaction at graphene/epoxy interface. Table 1 shows summary of representative investigations on the solvent processing.

As can be seen from Table 1, a wide range of solvents have been used for the dispersion of graphene, such as THF, DMF, acetone, ethanol, water, dichloromethane (DCM), methyl ethyl ketone (MEK), etc. Dispersion techniques like tip sonication, bath sonication, mechanical mix, shear mix, and three roll calendaring have been widely adopted for homogenous dispersion and most of these methods showed good results.

4.1.2 Resin impregnation. This method refers to impregnation of epoxy resin into the as-prepared graphene filter cake. It has not been widely reported in the literature until recently as a method for preparing polymer nanocomposites. Im et al. ${ }^{125}$ prepared a $60 \mathrm{wt} \%$ nanocomposite material by using this method for the very first time in 2012. They suspended GO particles in $\mathrm{H}_{2} \mathrm{O}$ under ultrasonication and then the prepared mixture was poured into a glass mould which was placed on a silicon oxide membrane. The mixture poured into the glass mould was filtered via vacuum filtration. After filtration, the filter cake, which was peeled off from the $\mathrm{SiO}_{2}$ membrane, was annealed under heating to remove the residual water. Finally, the epoxy containing the curing agent was dropped onto the filter cake and cured under heating. This method infuses epoxy resin into the graphene sheet by capillary driven wetting force and appropriate for fabricating highly concentrated nanocomposites with reasonably high mechanical properties.

Similar approach has been used by Li et al. ${ }^{\mathbf{1 2 6}}$ to fabricate a $11.84 \mathrm{wt} \%$ epoxy/graphene nanocomposite. They first dispersed

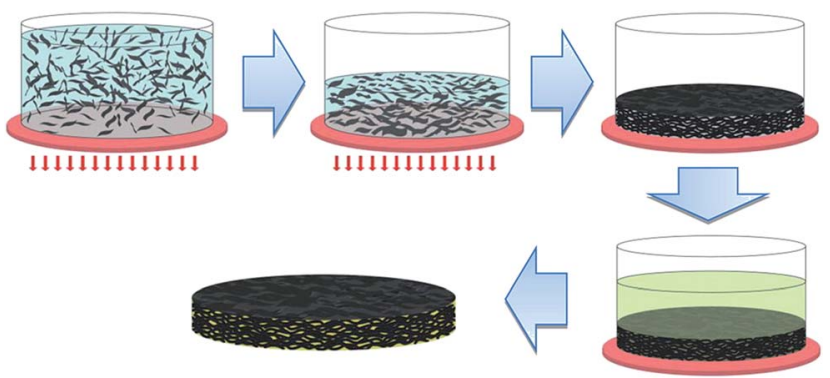

Fig. 5 Schematic diagram of the preparation of aligned epoxy/graphene. ${ }^{126}$ Reproduced with permission from ref. 126.

graphene platelets in the mixture of ethanol and water by ultrasonication and then removed the solvent by vacuum filtration. During the filtration process, self-assembly of the aligned graphene occurred (Fig. 5), after that they immersed this aligned graphene into epoxy monomer and curing agent. By this method, they prepared a nanocomposite with aligned multilayer graphene in epoxy matrix. The nanocomposite showed a thermal conductivity highly as $33.54 \mathrm{~W} \mathrm{~m}^{-1} \mathrm{~K}^{-1}$ at 90 ${ }^{\circ} \mathrm{C}$. This remarkable improvement in thermal conductivity was due to the unique alignment structure formed during processing.

Low filler percentage nanocomposites could also be prepared by this method. Jia et al. ${ }^{127}$ reported the preparation of a $0.1 \mathrm{wt} \%$ epoxy/graphene nanocomposite by impregnation of epoxy resin into a three dimensional (3D) graphene-nickel (Ni) foam via chemical vapour deposition, followed by curing of the polymer and etching of the Ni template. This nanocomposite with $0.1 \mathrm{wt} \%$ graphene delivered excellent fracture toughness, and the glass transition temperature increased $31^{\circ} \mathrm{C}$ compared to solid epoxy. More than that, they reported this 3D interconnected graphene network serves as fast channels for charge carriers, giving rise to a remarkable electrical conductivity of the nanocomposite.

4.1.3 Other methods. The most widely used method to prepare epoxy/graphene nanocomposites is through solvent processing. However, some derivative methods have also been adopted. Martin et al. ${ }^{\mathbf{1 2 8}}$ dispersed graphene in epoxy monomer by mechanical mixing. The mixture was then mixed with photo initiator and cured by UV irradiation. They reported enhancement in thermal and mechanical properties of the nanocomposite as a result of UV curing. Similarly, Sangermano et al. $^{\mathbf{1 2 9}}$ prepared UV cured epoxy/graphene nanocomposites as well and showed enhanced properties. Yu et al. ${ }^{130}$ used hot press in the curing procedure to fabricate the epoxy/graphene nanocomposite which showed several folds of increments in thermal conductivity. However, dispersing graphene in epoxy matrix without using solvent is likely to be less efficient. Hsu et al. ${ }^{\mathbf{1 3 1}}$ mixed graphene, epoxy monomer and curing agent all together using three roll milling at room temperature. Uniform dispersion of graphene was hindered by the high viscosity of epoxy resin, therefore, mixing without solvent might be considered as a less effective dispersion strategy. 


\subsection{Properties of nanocomposites}

Due to the recent developments in graphene and epoxy/graphene nanocomposites, the literature on this subject is still in its early stage but growing rapidly. However, some interesting studies have already been reported and will be discussed here to illustrate the potential of these new nanocomposites.

4.2.1 Morphology. As property enhancements strongly correlate with nanocomposite microstructure, ${ }^{\mathbf{1 3 2}}$ effective characterization of morphology is important to establish structureproperty relationships for these materials.

Transmission electron microscope (TEM) images of these nanocomposites can provide direct observation of dispersed multilayer graphene platelets. Thicker platelets typically shows adequate contrast against the epoxy matrix, whereas single layer platelets may be difficult to observe directly by TEM. ${ }^{133}$ Studies on layered nanofillers based nanocomposites have suggested the existence of three general states of dispersion on short length scales: stacked, intercalated, or exfoliated, as shown in Fig. 6.

TEM is the most common method for assessing the state of dispersion. Immiscibility of the phases and/or insufficient exfoliation of the graphite or graphene platelet prior to mixing with epoxy can result in large agglomerates consisting of stacked graphene sheets when observed by TEM. Fig. 7 shows

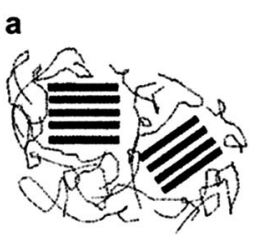

Stacked

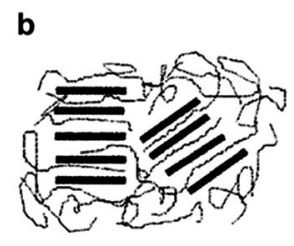

Intercalated

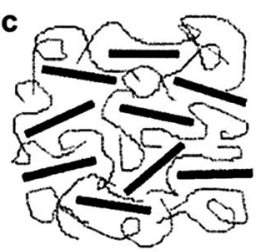

Exfoliated
Fig. 6 Schematic showing three morphological states for layered nanofillers based nanocomposites: ${ }^{134}$ (a) stacked, (b) intercalated, (c) exfoliated. Reproduced with permission from ref. 134.

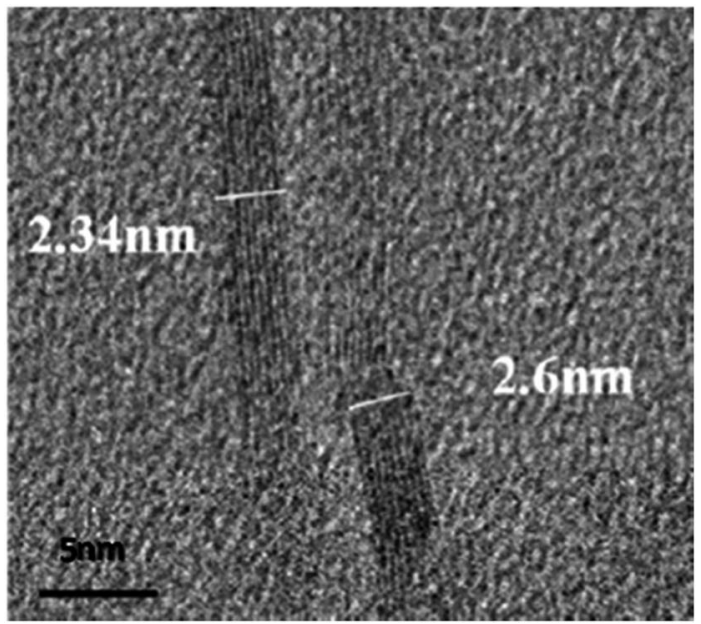

Fig. 7 TEM image of layered graphene in epoxy matrix. ${ }^{135}$ Reproduced with permission from ref. 135. an accurate measurement of the number of graphene layers in epoxy matrix.

The drawback of TEM is only a small area of the material could be observed, so cross sectional analysis with scanning electron microscopy (SEM) has also been used to evaluate dispersion of graphene as well as to examine the surface for filler pull-out, which could give insight into the strength of interfacial adhesion. ${ }^{\mathbf{1 3 6}}$ However, SEM image cannot resolve the degree of exfoliation of the platelets and is therefore best utilized combined with TEM. Furthermore, atomic force microscope (AFM) and the corresponding height profile graph is an important technique to characterize the pristine or functionalized graphene. The AFM study could give the length and thickness of graphene sheets along with morphology (Fig. 8). For AFM study, the sample is prepared by dispersing graphene in water or solvents and drop casting on a freshly cleaved mica surface. The dried sample is then observed through the instrument.

4.2.2 Mechanical properties. As previously mentioned, graphene has excellent mechanical properties namely high Young's modulus, high tensile strength, fracture toughness, etc. $^{\mathbf{1 3 8}}$ These exceptional properties make graphene an ideal candidate as filler for nanocomposite materials. Most of the work on epoxy/graphene nanocomposites is aimed at exploiting the remarkable mechanical enhancement effect of the graphene coupled with the possibility to introduce further functionalities, such as electrical conductivity ${ }^{\mathbf{1 3 9}}$ or thermal stability. ${ }^{\mathbf{1 4 0}}$

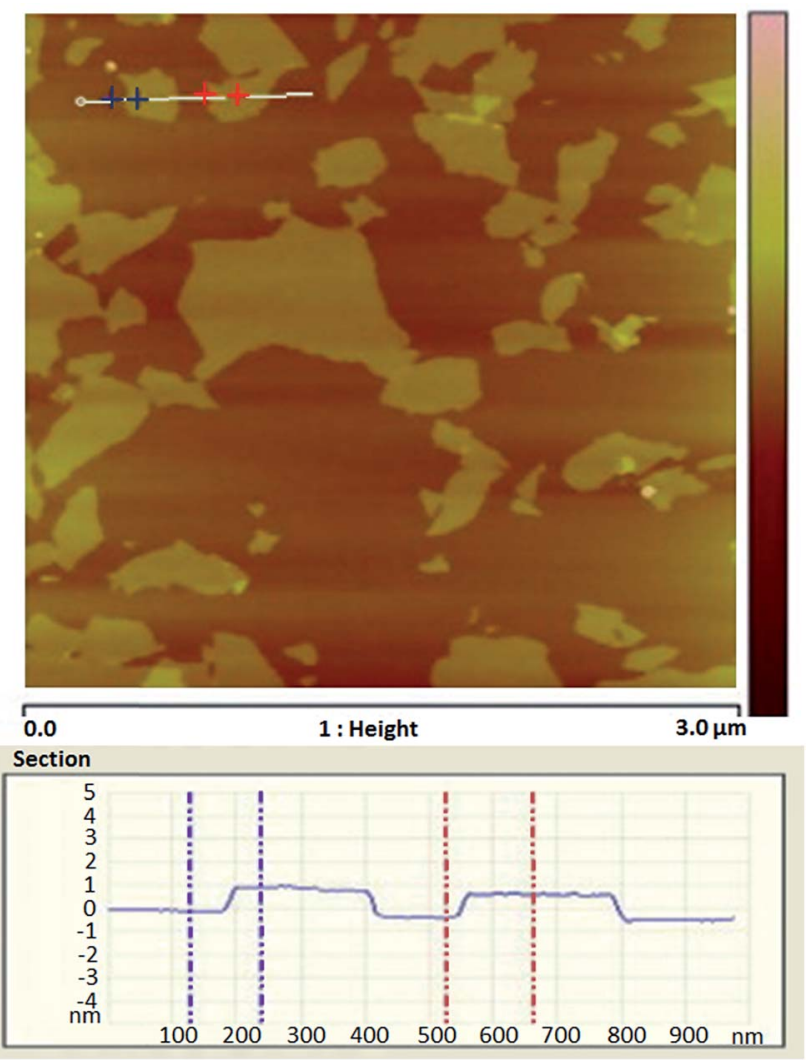

Fig. 8 AFM image and height profile of graphene. ${ }^{137}$ Reproduced with permission from ref. 137. 

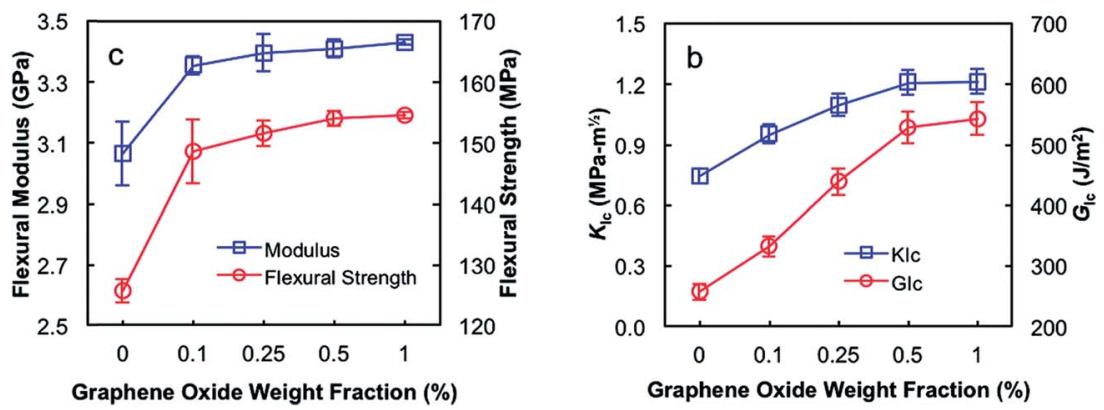

Fig. 9 Quasi-static mechanical properties of epoxy nanocomposites. ${ }^{119}$ Reproduced with permission from ref. 119

Recently, Bortz et al. ${ }^{119}$ conducted the investigation on the mechanical properties of epoxy/graphene oxide nanocomposites. The study showed the influence of graphene oxide concentration $(0.1,0.25,0.5$ and $1 \mathrm{wt} \%)$ on the fracture toughness and flexural strength of nanocomposites which are presented in Fig. 9. The graphs showed that with the increase in graphene oxide concentration, the mechanical properties of nanocomposites increased as well. For example, at the concentration of $1 \mathrm{wt} \%$, the nanocomposite showed more than one hundred percent increase in $G_{\mathrm{IC}}$. Qi et al. ${ }^{141}$ used thermotropic liquid crystalline epoxy to functionalize the graphene surface. The fabricated nanocomposites showed enhancement in tensile strength from $55.43 \mathrm{MPa}$ to $78.96 \mathrm{MPa}$ at $1 \mathrm{wt} \%$ accompanied by nearly one hundred percent increase in impact strength. Similarly, Liu et al. ${ }^{142}$ investigated the interphase of epoxy/graphene oxide and reported increase in the modulus and toughness. Fracture toughness and flexural modulus were increased with the increasing filler concentration which indicated the significant enhancement effect of graphene in epoxy matrix.

As discussed in the previous sections, dispersion of graphene plays a very crucial role in the preparation of epoxy/ graphene nanocomposites, ${ }^{143}$ for which many different techniques have been investigated. A homogenous dispersion could give better load transfer to filler material which results into better mechanical properties for the graphene nanocomposites. ${ }^{144}$ For example, Li et al. ${ }^{115}$ incorporated $0.5 \mathrm{wt} \%$ silane functionalized graphene into epoxy matrix by mechanical mixing and bath sonication and reported $20 \%$ increase in elastic modulus and $16 \%$ increase in tensile strength as compared to neat epoxy. Similarly, Rafiee et al. ${ }^{96}$ reported a significant enhancement of Young's modulus at $0.1 \mathrm{wt} \%$ of epoxy/graphene nanocomposites processed by shear mixing and tip sonication. For well dispersed nanocomposites, improved mechanical interlocking with polymer chains and graphene can be observed, and slipping of entrapped polymer molecules was suppressed, along with improved dispersion, tensile strength and fracture toughness. Izzuddin et al. ${ }^{118}$ reported that the presence of good adhesion between graphene and matrix were the main attributes for these increments. In order to form a strong interface, polyoxyalkyleneamine functionalized graphene were dispersed in epoxy matrix by bath sonication and mechanical mixing, and it was evident that the functionalization treatment increased modulus and fracture properties of the nanocomposites. In their report, the samples with $0.489 \mathrm{vol} \%$ functionalized graphene, showed $224 \%$ improvement in the fracture toughness as compared to the pure resin. Therefore, functionalization of graphene has significant positive effect on the mechanical properties of the epoxy nanocomposites.

4.2.3 Electrical conductivity. A number of studies, related to the electrical properties of polymer/graphene nanocomposites, have been conducted. ${ }^{145}$ The combination of graphene and polymer matrices offers new attractive electrical properties and novel conducting polymers. These polymers can be used for various engineering applications like, electrical conducting adhesives, antistatic coating and films, electromagnetic interference shielding materials for electronic devices, thermal interface materials, etc. ${ }^{146}$ These conducting nanocomposites follow the principle of percolation theory which basically explains the transition from insulator to conductor in materials. The percolation threshold is the concentration at which the electrical conductivity of an insulating polymer matrices increases dramatically. A conductive continuous network of filler is created and electrons can be transported by direct contact among nanofiller particles, beyond this concentration, the conductivity of the nanocomposite increases marginally. ${ }^{147}$

The electrical conduction in a nanocomposite is due to the formation of a continuous conductive network formed by the fillers. Therefore, aligned nanofillers have higher probabilities to percolate at lower volumetric concentrations than spherical nanofillers. ${ }^{148}$ Graphene becomes an ideal candidate to achieve this percolated network at low loading fractions due to its intrinsically high conductivity and the $2 \mathrm{D}$ structure. Wajid et al. ${ }^{110}$ reported the ultra-low electrical percolation threshold at $0.088 \mathrm{vol} \%$ in epoxy/graphene nanocomposites, by dispersing graphene with the assistance of tip sonication, mechanical mixing and shear mixing. Similarly, Liang et al. ${ }^{124}$ also reported significant increase in the electrical conductivity by incorporating graphene in epoxy nanocomposites matrix by bath sonication and mechanical mixing. The conductivity was improved from $0.8 \times 10^{-10}$ to $0.8 \times 10^{-2}$ by incorporating 8 vol\% reduced graphene oxide into epoxy. Such improvements are only possible when graphene are thoroughly de-bundled and homogenously dispersed in epoxy matrix. Monti et al. ${ }^{149}$ 
dispersed graphene into epoxy to study the electrical conductivities. In order to improve the dispersion, they processed the mixture by tip sonication and mechanical mixing and used different solvents such as chloroform or THF. The highest electrical conductivity was observed for sample with 3 wt $\%$ graphene. It was also shown that the thermal conductivity increased with the increase in graphene concentration.

4.2.4 Thermal conductivity. As opposed to the electrical conductivity, the thermal conductivity of epoxy/graphene nanocomposites has received less attention to date. As compared to electrical conductivity enhancements of several orders of magnitude, thermal conductivity enhancement by the carbon nanofillers is not as significant. ${ }^{\mathbf{1 5 0}}$ However, several folds increment in thermal conductivity can easily be obtained, as it has been reported that the $2 \mathrm{D}$ shape platelets like graphene nanosheets can improve thermal conductivity more effectively than 1D rod like carbon nanotube (CNT). ${ }^{\mathbf{9 2 , 1 5 1}}$ As given by Kapitza resistance, the transfer of thermal energy are carried out by the free electrons interaction and lattice vibration between the two contacted interface. Therefore, poor coupling at the filler/polymer interfaces will significantly impact on thermal resistance. ${ }^{152}$ Hence, a strong filler/polymer interface is required to achieve good thermal conductivity. ${ }^{153}$

Veca et al. ${ }^{151}$ applied alcohol and oxidative acid treatment with the assistance of extended and vigorous sonication to thermally expanded graphite. Carbon nanosheets were found well dispersed in epoxy matrix with a thickness of less than 10 $\mathrm{nm}$. The incorporation of $33 \mathrm{vol} \%$ carbon nanosheets could improve the in plane thermal conductivity of epoxy nanocomposites to $80 \mathrm{~W} \mathrm{~m} \mathrm{~m}^{-1} \mathrm{~K}^{-1}$. However, the across-plane thermal conductivity was found only one-tenth to one-fifth of the average in-plane value. This highly anisotropic nature resulted from the 2D structure of the graphene sheets. Wang et al. ${ }^{154}$ reported that $5 \%$ graphite oxide (prepared via thermal expansion) increased the thermal conductivity of epoxy to over $0.8 \mathrm{~W} \mathrm{~m} \mathrm{~m}^{-1} \mathrm{~K}^{-1}$ and decreased the coefficient of thermal expansion by $31.7 \%$ below $T_{\mathrm{g}}$. Ganguli et al. ${ }^{92}$ found that $20 \mathrm{wt} \%$ silane functionalized thermally expanded graphite enhanced

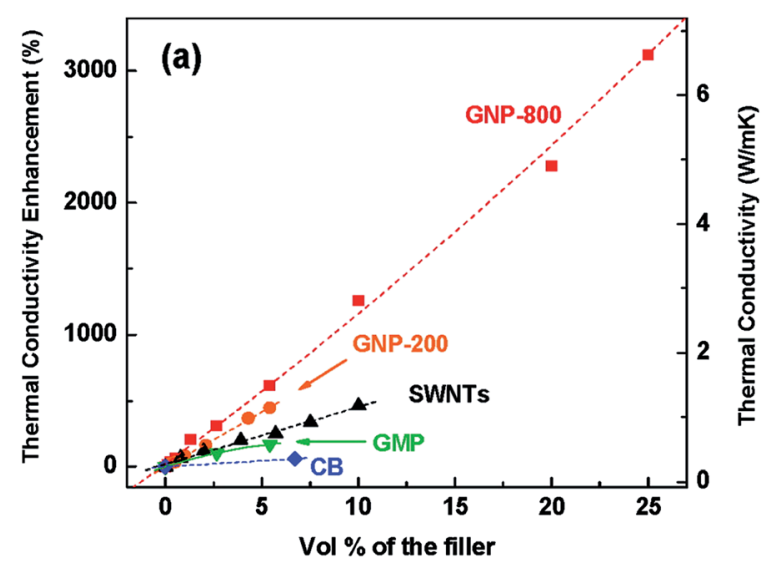

Fig. 10 Thermal conductivity enhancement of epoxy-based nanocomposites. ${ }^{155}$ Utilized fillers: graphitic microparticles (GMP), GNPs exfoliated at $200{ }^{\circ} \mathrm{C}(\mathrm{GNP}-200)$ and $800{ }^{\circ} \mathrm{C}$ (GNP-800), carbon black (CB) and SWNTs. Reproduced with permission from ref. 155. the thermal conductivity of epoxy from 0.2 to $5.8 \mathrm{~W} \mathrm{~m}^{-1} \mathrm{~K}^{-1}$. It was interesting to find that silane functionalization could form covalent bonding with epoxy and improved the interfacial heat transfer between two components by reducing acoustic impedance mismatch in the interfacial area. However, excessive functionalization also tends to reduce the intrinsic thermal conductivity of carbon materials. Fig. 10 shows a larger contribution of graphene for the thermal conductivity for epoxy matrix as compared to CNTs and carbon black.

4.2.5 Thermal stability. Several studies have evaluated the effect of graphene on the thermal properties in many polymer matrices, such as thermal degradation temperature, ${ }^{\mathbf{1 5 6}}$ glass transition temperature ${ }^{157}$ melting temperature ${ }^{158}$ and polymer crystallinity of the nanocomposites. ${ }^{159}$ However, there is no melting temperature for epoxy because of its thermosetting nature, so glass transition and thermal degradation behaviours are among the most important characters to characterize the thermal stability of epoxy nanocomposites which have been discussed in this section.

It is generally observed that graphene would enhance the $T_{\mathrm{g}}$ of epoxy matrix. ${ }^{\mathbf{1 6 0}}$ This is due to the adhesion force between epoxy and graphene which reduces the mobility of epoxy chains on graphene surface. Contrarily, decrease in $T_{\mathrm{g}}$ is expected for weakly adhering fillers and unstable interfaces facilitating the chain polymer mobility, thus lowering the $T_{\mathrm{g} \cdot{ }^{161}} \mathrm{Li}$ et al. ${ }^{162}$ reported the increase in $T_{\mathrm{g}}$ of epoxy by hindering segmental motion of polymer chains via mechanical interlocking and hydrogen bonding with surface oxygen functionalities. Similarly, a $T_{\mathrm{g}}$ increase of $14{ }^{\circ} \mathrm{C}$ in epoxy/graphene nanocomposites has been measured by Park et al. ${ }^{163}$ at $1 \mathrm{phr}$ (parts per hundred resin) of graphene in epoxy matrix. This is an expected outcome of the strong filler-matrix adhesion and because of the conformational changes of the epoxy matrix at the epoxy/graphene interface.

In contrary, a significant volume of research reported the opposite trend and will be discussed here. It has been vastly reported that graphene reduces the glass transition or thermal degradation temperature of epoxy matrix and there is no unanimous agreement for this negative trend. Galpaya et al. ${ }^{\mathbf{1 6 4}}$ proposed the theory that the $T_{\mathrm{g}}$ of nanocomposites depends on the balance of two effects, i.e., influence on reaction conversion and molecular confinement. Graphene sheets are stiffer than epoxy matrix which could lead to significant confinement on the polymer chains. On the other hand, graphene sheets may impede the epoxy curing reaction. The reason could be the functional groups on graphene surface reacting with the curing agent and/or epoxy resin, or graphene sheets covering the reactive sites in the resin due to its high surface area. If the latter one plays the dominant role, it would be expected to reduce the polymer cross link density and would also increase polymer chain mobility. Liao et al. ${ }^{70}$ and Kim et al. ${ }^{123}$ reported similar conclusions as well. According to them, the incorporation of graphene reduces the cross link density of the epoxy matrix, which results in the decrease of $T_{\mathrm{g}}$. Some research groups like Saurín et al. ${ }^{165}$ Liu et al. ${ }^{166}$ and Guo et al. ${ }^{91}$ reported that graphene acts as reactive plasticizer and has a plasticizing effect on epoxy resin, thus increasing the flexibility of chain 
segments of the epoxy matrix. Liu et al. ${ }^{120}$ prepared an epoxy/ imidazole functionalized graphene nanocomposite and reported that the short molecular chains of functional group on graphene surface are flexible and would result in an overall $T_{\mathrm{g}}$ decrease. There are also some other claims, such as Liu et al. ${ }^{167}$ incorporated edge functionalized graphene into epoxy resin and found that the $T_{\mathrm{g}}$ decreased because of the existence of graphene sheets that could result in increased flexibility of the network. Zhang et al. ${ }^{168}$ prepared magnetic graphene reinforced epoxy nanocomposites and reported that the rigid structure of graphene nanoplatelets would cause extra enlarged free volume, which is detrimental to the thermal stability of the matrix.

For thermal decomposition temperatures $\left(T_{\mathrm{d}}\right)$, which are characterized by the maximum weight loss rate in thermogravimetry, shifts up to $30{ }^{\circ} \mathrm{C}$ for epoxy nanocomposites by incorporating $0.5 \mathrm{wt} \%$ functionalized graphene were reported. ${ }^{\mathbf{1 0 5}}$ Decomposition of graphene nanocomposites is substantially slower than neat epoxy, which is attributed to restricted chain mobility of polymers near the graphene surface. Similarly, Prolongo et al. ${ }^{169}$ reported that $0.5 \mathrm{wt} \%$ graphene nanoplatelet can push the thermal degradation temperature of epoxy from $377^{\circ} \mathrm{C}$ to $397^{\circ} \mathrm{C}$. Yousefi et al. ${ }^{114}$ reported that both graphene oxide and reduced graphene oxide improved the thermal decomposition temperature of epoxy matrix. Fig. 11 shows the shift in thermal gravimetric analysis (TGA) curves to higher temperature, which means a higher thermal stability due to the incorporation of graphene.

Wang et al. ${ }^{170}$ and Xin et al. ${ }^{171}$ incorporated functionalized graphene into epoxy matrix and reported decrease in $T_{\mathrm{d}}$. This was due to the presence of thermally unstable chemicals, which on decomposition, lowered $T_{\mathrm{d}}$ as compared to monolithic epoxy. Feng et al. ${ }^{111}$ used epoxy resin to modify graphene first, and then mixed with the epoxy matrix. They found that in some cases, the $T_{\mathrm{d}}$ of the nanocomposite decreased because the filler might causes defects in the polymeric networks during the curing process.

In general, it is widely acknowledged that graphene could enhance the thermal stability of epoxy. However, there are still many controversies where many researchers reported a decrease

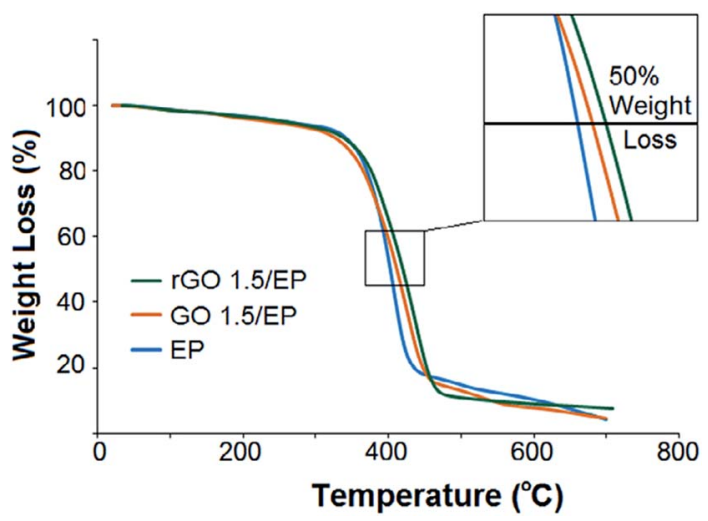

Fig. 11 TGA curves of epoxy nanocomposites containing GO and rGO. ${ }^{114}$ Reproduced with permission from ref. 114. in thermal properties of epoxy with the incorporation of graphene. The reason of such has not been fully explained and requires deeper understanding via extensive further research.

4.2.6 Flame retardant properties. Engineering materials are required to resist degradation during an unlikely event of fire in many critical applications like skyscrapers, boats, or airplanes. ${ }^{172}$ In fact, some studies reported that about $20 \%$ of victims of airplane crashes are killed not by the crash itself but by ensuing fires. ${ }^{173}$ Materials used in aviation should be designed to inhibit, suppress, or delay the production of flames to prevent the spread of fire. Flame retardant materials are mainly based on halogen, phosphorus, inorganic, and melamine compounds, ${ }^{174}$ however, among these flame retardants, only inorganic fillers are normally nontoxic. ${ }^{175}$ Current research on epoxy/graphene nanocomposites has been focused on improving the flame retardant properties such as ease of ignition, limiting oxygen index, rate of heat release, and the evolution of smoke and toxic gases by incorporating modified graphene, along with improving the physical properties of the epoxy matrix. ${ }^{176-178}$ For example, Li et al. ${ }^{179}$ used 2-(diphenylphosphino)ethyltriethoxy silane modified graphene oxide, and then incorporated this modified graphene oxide into epoxy matrix. They found that the limiting oxygen index increased from 20 to 36, which means a huge transition of material's nature from flammable to non-flammable. Jiang et al. ${ }^{180}$ prepared epoxy/graphene-ZnS nanocomposites and reported that with the incorporation of $\mathrm{ZnS}$ decorated graphene, the carbon monoxide production rate for the nanocomposites is much lower than that of pure epoxy along with decreased total smoke release. Wang et al. ${ }^{181}$ prepared Ni-Fe Layered Double Hydroxide (LDH) modified graphene/epoxy nanocomposites. They found that with the incorporation of $2 \mathrm{wt} \% \mathrm{Ni}-\mathrm{Fe} \mathrm{LDH}$ modified graphene, the ignition time of epoxy matrix increased from $68 \mathrm{~s}$ to $89 \mathrm{~s}$, the total heat release decreased from $113.1 \mathrm{MJ}$ $\mathrm{m}^{-2}$ to $44.2 \mathrm{MJ} \mathrm{m}^{-2}$, and the fire growth index decreased from $13.3 \mathrm{~kW} \mathrm{~m}^{-2} \mathrm{~s}^{-1}$ to $4.8 \mathrm{~kW} \mathrm{~m}^{-2} \mathrm{~s}^{-1}$. Fig. 12 shows the drastic decrease of heat release rate with the incorporation of graphene and Ni-Fe LDH modified graphene.

Zhuo et al. ${ }^{182}$ proposed a flame retarding mechanism for polymer matrices when filled with graphene. According to Zhuo et al. ${ }^{182}$ the barrier effect of graphene plays a dominant role in flame retardancy. Graphene walls make excellent gas barriers which delay the oxidative degradation of epoxy during a fire, moreover, the large surface area of graphene can induce a large amount of char which prevents the resin from suffering heat.

In general, the addition of graphene into epoxy matrix results in improving flame retardancy and thermal stability of epoxy along with improved mechanical properties. Moreover, no environmental or toxicity issues have been reported for graphene. Therefore, it can be concluded that graphene has a great potential to be one of the most promising flame retarding fillers for nanocomposites in near future.

4.2.7 Synergic effects with other fillers. Synergic effect or hybridisation means incorporation of two or more fillers together for enhanced functionality which is not possible to achieve with single filler alone. Recently, a tremendous research effort can be witnessed to generate enhanced properties by 
Table 2 Synergic effect of graphene and other fillers in epoxy matrix

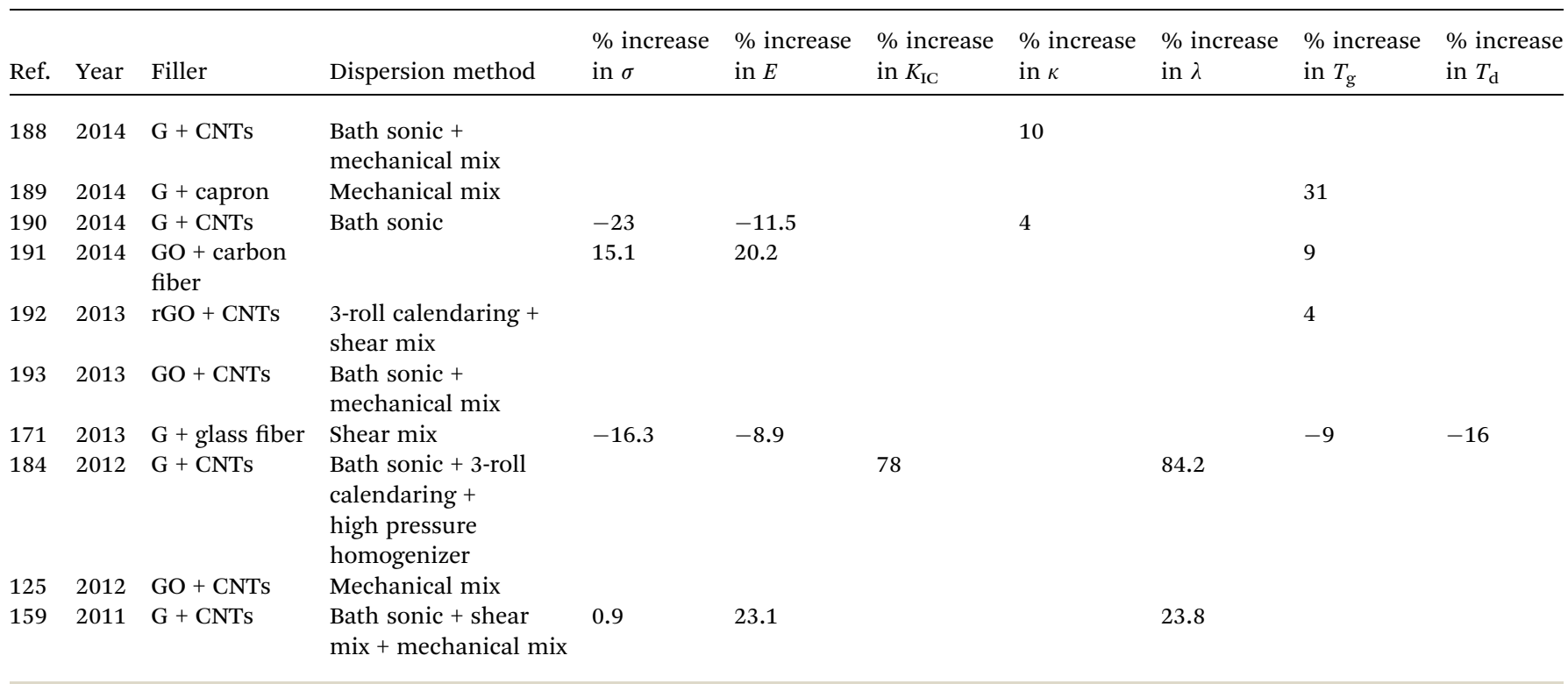

synergistically combining different fillers as reported by Inam et al. ${ }^{183}$ The group fabricated multiscale epoxy composites which showed enhanced mechanical properties with the combination of carbon nanotubes and carbon fibers. Chatterjee et al. ${ }^{184}$ found that the CNT : GNP ratio is an interesting factor influencing the properties of the epoxy based nanocomposites. At nanofiller concentration of $0.5 \mathrm{wt} \%$, highest CNT content $(9: 1)$ showed marked improvement in fracture toughness of $76 \%$. Kumar et al. ${ }^{185}$ suggested that by bringing together two nanofillers like CNT and GNP, they could form a co-supporting network. This net-resemble structure could shield the fillers from fracture and damage during processing, while still allowing full dispersion of both filler during high power sonication, thus resulting improved properties. Apart from the mechanical properties, incorporation of carbon fillers in polymer matrices attained significance for the applications where enhanced thermal and electrical conductivity were required together.

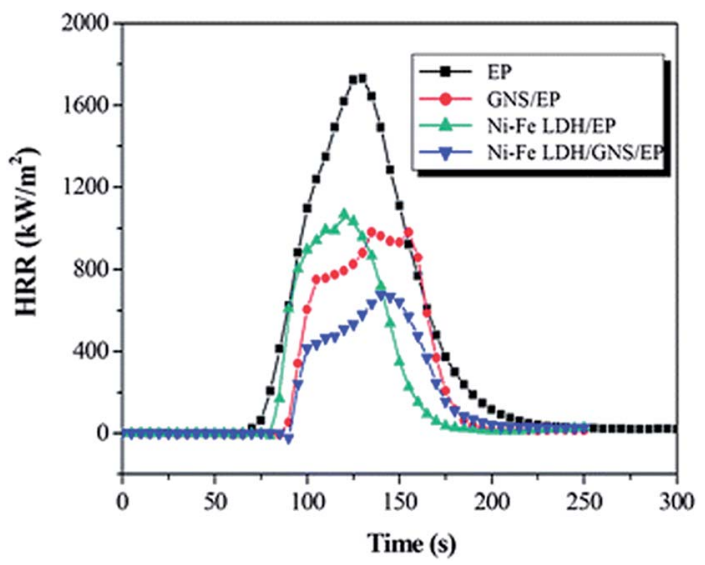

Fig. 12 Heat release rate versus time curves of epoxy and its nanocomposites. ${ }^{181}$ Reproduced with permission from ref. 181.
Epoxy resins containing a binary mixture of GNP and single wall carbon nanotube (SWCNT) in $3: 1$ weight ratio have higher thermal conductivity than those reinforced with either individual fillers. Yu et al. ${ }^{186}$ explained this synergistic effect by bridging interactions between GNP and SWCNT which can reduce the interfacial resistance for thermal conduction. Also, a remarkable synergetic effect between graphene platelets and multiwalled carbon nanotubes (MWCNTs) in improving the mechanical properties and thermal conductivity of epoxy nanocomposites was demonstrated by Yang et al. ${ }^{159}$ The tensile strength and thermal conductivity were increased by $35.4 \%$ and $146.9 \%$ respectively by using MWCNT/graphene fillers as compared to either filler for epoxy nanocomposites. They found that stacking of individual 2D graphene is effectively inhibited by introducing 1D MWCNTs. Long and tortuous MWCNTs can bridge adjacent graphene platelets and inhibit their agglomeration, resulting in a high contact area between the MWCNT/ graphene structures and the polymer matrices. ${ }^{159}$

In general, the exact mechanism responsible for this dramatic enhancement is not entirely understood. It is widely believed that molecular level interactions between the nanomaterials and polymer matrices play a major role. The large interface area available for such interactions clearly hold the key for this dramatic enhancement in mechanical properties. ${ }^{187}$ Table 2 lists some representative papers which adopt multi filler or hybridisation approach to modify the properties of epoxy matrix.

\section{Conclusions}

Graphene shows great potential as filler for the next generation advanced nanocomposite materials. Numerous efforts have been made to prepare useful epoxy/graphene nanocomposites. However, the development and applicability of epoxy/graphene nanocomposites will be significantly related to the dispersion 
and the interfacial bonding of graphene in epoxy matrix, which are the two most critical factors to determine the performance of these novel nanocomposites. Thus, the key to prepare advanced epoxy/graphene nanocomposites is to improve the techniques for the dispersion of graphene and engineering the graphene-epoxy interface. This review provided a detailed introduction of epoxy/graphene nanocomposites and critical analyses on recent research investigations. Following conclusions can be drawn from the existing reported research:

- Graphene has significant potential for epoxy based composites. Extremely enhanced multi-functional properties can be achieved subject to homogenous dispersion and strong interfacial interactions. Chemical functionalization of graphene can also significantly improve the graphene-epoxy interfacial interactions.

- Solvent processing is the most widely adopted method to prepare epoxy/graphene nanocomposites. The high viscosity of epoxy may hinder the uniform dispersion of graphene and therefore, it is also difficult to adopt solvent-free processing approach.

- Mechanical properties, electrical conductivity, thermal conductivity, thermal stability and flame retardant properties are generally increased with the incorporation of graphene.

- Graphene could increase the glass transition and thermal degradation temperatures of epoxy nanocomposite. However, this needs to be further explored as some investigations have reported the negative trend.

In general, epoxy/graphene materials have remarkably high thermal and electrical conductivities, as well as improved mechanical strength and thermal stability. Because of these excellent properties, graphene reinforced epoxy nanocomposites possess great potential to be used in automotive, electronics, aerospace and for other sectors. However, a lot is still required to be understood before such applications can be materialised.

\section{Acknowledgements}

The authors would like to thank the Department of Mechanical and Construction Engineering, Northumbria University for the provision of facilities, without which the collection of relevant data was not possible.

\section{References}

1 O. V. Yazyev and Y. P. Chen, Nat. Nanotechnol., 2014, 9, 755767.

2 X. Huang, X. Qi, F. Boey and H. Zhang, Chem. Soc. Rev., 2012, 41, 666-686.

3 R. J. Young, I. A. Kinloch, L. Gong and K. S. Novoselov, Compos. Sci. Technol., 2012, 72, 1459-1476.

4 S. Deng, L. Djukic, R. Paton and L. Ye, Composites, Part A, 2015, 68, 121-132.

5 G. Mittal, V. Dhand, K. Y. Rhee, S. J. Park and W. R. Lee, J. Ind. Eng. Chem., 2015, 21, 11-25.

6 F. Inam and T. Peijs, Adv. Compos. Lett., 2006, 15, 7-13.

7 S. Ye, J. Feng and P. Wu, J. Mater. Chem. A, 2013, 1, 3495.
8 Y. Heo, H. Im, J. Kim and J. Kim, J. Nanopart. Res., 2012, 14, $1-10$.

9 X. Wang, W. Xing, X. Feng, B. Yu, H. Lu, L. Song and Y. Hu, Chem. Eng. J., 2014, 250, 214-221.

10 J. E. An and Y. G. Jeong, Eur. Polym. J., 2013, 49, 1322-1330.

11 Y. Yang, Z. H. Xu, Z. Pan and X. Li, Adv. Mater., 2012, 24, 881-885.

12 S. Kango, S. Kalia, A. Celli, J. Njuguna, Y. Habibi and R. Kumar, Prog. Polym. Sci., 2013, 38, 1232-1261.

13 L. Guadagno, M. Raimondo, V. Vittoria, L. Vertuccio, C. Naddeo, S. Russo, B. de Vivo, P. Lamberti, G. Spinelli and V. Tucci, RSC Adv., 2014, 4, 15474.

14 P. Mohan, Polym.-Plast. Technol. Eng., 2013, 52, 107-125.

15 F. Inam, Epoxy, 2014, 1, 1-2.

16 D. Ratna, J. Adhes. Sci. Technol., 2003, 17, 1655-1668.

17 J. H. Hodgkin, G. P. Simon and R. J. Varley, Polym. Adv. Technol., 1998, 9, 3-10.

18 S. V. Levchik and E. D. Weil, Polym. Int., 2004, 53, 19011929.

19 M. B. Jakubinek, B. Ashrafi, Y. Zhang, Y. Martinez-Rubi, C. T. Kingston, A. Johnston and B. Simar, Composites, Part $B, 2015,69,87-93$.

20 K. S. Novoselov, A. K. Geim, S. V. Morozov, D. Jiang, Y. Zhang, S. V. Dubonos, I. V. Grigorieva and A. A. Firsov, Science, 2004, 306, 666-669.

21 A. Y. W. Sham and S. M. Notley, Soft Matter, 2013, 9, 6645. 22 http://graphene-flagship.eu.

23 Y. Zhu, S. Murali, W. Cai, X. Li, J. W. Suk, J. R. Potts and R. S. Ruoff, Adv. Mater., 2010, 22, 3906-3924.

24 S. Park and R. S. Ruoff, Nat. Nanotechnol., 2009, 4, 217-224.

25 R. L. D. Whitby, ACS Nano, 2014, 8, 9733-9754.

26 J. H. Chen, C. Jang, S. Xiao, M. Ishigami and M. S. Fuhrer, Nat. Nanotechnol., 2008, 3, 206-209.

27 A. S. Mayorov, R. V. Gorbachev, S. V. Morozov, L. Britnell, R. Jalil, L. A. Ponomarenko, P. Blake, K. S. Novoselov, K. Watanabe, T. Taniguchi and A. K. Geim, Nano Lett., 2011, 11, 2396-2399.

28 A. Kamyshny and S. Magdassi, Small, 2014, 10, 3515-3535.

29 X. Yang, C. Cheng, Y. Wang, L. Qiu and D. Li, Science, 2013, 341, 534-537.

30 K. Kim, S. H. Bae, C. T. Toh, H. Kim, J. H. Cho, D. Whang, T. W. Lee, B. Özyilmaz and J. H. Ahn, ACS Appl. Mater. Interfaces, 2014, 6, 3299-3304.

31 D. Prasai, J. C. Tuberquia, R. R. Harl, G. K. Jennings and K. I. Bolotin, ACS Nano, 2012, 6, 1102-1108.

32 K. Sambasivudu and M. Yashwant, Nanotech Insights, 2012. 33 H. Fernandezmoran, J. Appl. Phys., 1960, 31, 1844.

34 C. Soldano, A. Mahmood and E. Dujardin, Carbon, 2010, 48, 2127-2150.

35 W. Ren and H. M. Cheng, Nat. Nanotechnol., 2014, 9, 726730.

36 K. R. Paton, E. Varrla, C. Backes, R. J. Smith, U. Khan and T. J. Pennycook, Nat. Mater., 2014, 13, 624-630.

37 I. Y. Jeona, Y. R. Shina, G. J. Sohna, H. J. Choia and J. B. Baeka, Proc. Natl. Acad. Sci. U. S. A., 2012, 109, 55885593.

38 S. F. Pei, Chinese patent ZL.201110282370.5, 2011. 
39 R. V. Noorden, Nature, 2012, 483, S32-S33.

40 S. R. Na, J. W. Suk, L. Tao, D. Akinwande, R. S. Ruoff, R. Huang and K. M. Liechti, ACS Nano, 2015, 9, 1325-1335.

41 X. Li, W. Cai, J. An, S. Kim, J. Nah, D. Yang and R. S. Ruoff, Science, 2009, 324, 1312-1314.

42 K. S. Kim, Y. Zhao, H. Jang, S. Y. Lee and B. H. Hong, Nat. Mater., 2009, 457, 706-710.

43 G. Mittal, V. Dhand, K. Y. Rhee, S. J. Park and W. R. Lee, J. Ind. Eng. Chem., 2015, 21, 11-25.

44 S. Pei and H. Cheng, Carbon, 2012, 50, 3210-3228.

45 J. Yao, Y. Sun, M. Yang and Y. Duan, J. Mater. Chem., 2012, 22, 14313-14329.

46 Z. Wu, W. Ren, L. Gao, J. Zhao, Z. Chen, B. Liu, D. Tang, B. Yu, C. Jiang and H. Cheng, ACS Nano, 2009, 2, 411-417.

47 W. Zhang, J. Cui, C. A. Tao, Y. Wu, Z. Li, L. Ma, Y. Wen and G. Li, Angew. Chem., Int. Ed., 2009, 121, 5978-5982.

48 Y. Shao, J. Wang, M. Engelhard, C. Wang and Y. Lin, J. Mater. Chem., 2010, 20, 743-748.

49 J. Sakamoto, J. V. Heijst, O. Lukin and A. D. Schlüter, Angew. Chem., Int. Ed., 2009, 48, 1030-1069.

50 C. Soldano, A. Mahmood and E. Dujardin, Carbon, 2010, 48, 2127-2150.

51 S. Guo and S. Dong, Chem. Soc. Rev., 2011, 40, 2644-2672.

52 A. M. Coclite, R. M. Howden, D. C. Borrelli, C. D. Petruczok, R. Yang, J. L. Yague, A. Ugur, N. Chen, S. Lee, W. J. Jo, A. Liu, X. Wang and K. K. Gleason, Adv. Mater., 2013, 25, 53925423.

53 W. Hummersjr and R. Offeman, J. Am. Chem. Soc., 1958, 80, 1339.

54 L. Staudenmaier, Ber. Dtsch. Chem. Ges., 1898, 31, 14811487.

55 B. C. Brodie, Ann. Chim. Phys., 1860, 59, 466.

56 X. Hu, R. Qi, J. Zhu, J. Lu, Y. Luo, J. Jin and P. Jiang, J. Appl. Polym. Sci., 2014, 131, 39754.

57 H. He, J. Klinowski, M. Forster and A. Lerf, Chem. Phys. Lett., 1998, 287, 53-56.

58 J. I. Paredes, S. Villar-Rodil, A. Martinez-Alonso and J. M. D. Tascon, Langmuir, 2008, 24, 10560-10564.

59 A. Zurutuza and C. Marinelli, Nat. Nanotechnol., 2014, 9, 730-734.

60 F. Inam, A. Heaton, P. Brown, T. Peijs and M. J. Reece, Ceram. Int., 2014, 40, 511-516.

61 A. S. Wajid, S. Das, F. Irin, H. S. T. Ahmed, J. L. Shelburne, D. Parviz, R. J. Fullerton, A. F. Jankowski, R. C. Hedden and M. J. Green, Carbon, 2012, 50, 526-534.

62 K. M. Liew, Z. X. Lei and L. W. Zhang, Compos. Struct., 2015, 120, 90-97.

63 J. Kim, B. S. Yim, J. M. Kim and J. Kim, Microelectron. Reliab., 2012, 52, 595-602.

64 J. K. Lee, S. Song and B. Kim, Polym. Compos., 2012, 33, 1263-1273.

65 S. L. Qiu, eXPRESS Polym. Lett., 2011, 5, 809-818.

66 J. Kim, H. Im, J. M. Kim and J. Kim, J. Mater. Sci., 2011, 47, 1418-1426.

67 T. Jiang, T. Kuila, N. H. Kim, B. C. Ku and J. H. Lee, Compos. Sci. Technol., 2013, 79, 115-125.

68 R. K. Layek and A. K. Nandi, Polymer, 2013, 54, 5087-5103.
69 K. Hu, D. D. Kulkarni, I. Choi and V. V. Tsukruk, Prog. Polym. Sci., 2014, 39, 1934-1972.

70 S. H. Liao, P. L. Liu, M. C. Hsiao, C. C. Teng, C. A. Wang, M. D. Ger and C. L. Chiang, Ind. Eng. Chem. Res., 2012, 51, 4573-4581.

71 V. Georgakilas, Functionalization of Graphene, 2014.

72 M. J. Park, J. K. Lee, B. S. Lee, Y. W. Lee and S. G. Lee, Chem. Mater., 2006, 18, 1546-1551.

73 T. Kuila, S. Bose, A. K. Mishra, P. Khanra, N. H. Kim and J. H. Lee, Prog. Mater. Sci., 2012, 57, 1061-1105.

74 H. Yang, C. Shan, F. Li, D. Han, Q. Zhang and L. Niu, Chem. Commun., 2009, 3880-3882, DOI: 10.1039/b905085j.

75 C. Bao, Y. Guo, L. Song, Y. Kan, X. Qian and Y. Hu, J. Mater. Chem., 2011, 21, 13290.

76 D. Cai and M. Song, J. Mater. Chem., 2010, 20, 7906.

77 J. Fan, Z. Shi, J. Wang and J. Yin, Polymer, 2013, 54, 39213930.

78 V. E. Muradyan, A. A. Arbuzov, E. A. Sokolov, S. D. Babenko and G. V. Bondarenko, Tech. Phys. Lett., 2013, 39, 798-800.

79 X. Wang, W. Xing, X. Feng, B. Yu, L. Song and Y. Hu, Polym. Chem., 2014, 5, 1145.

80 S. H. Song, K. H. Park, B. H. Kim, Y. W. Choi, G. H. Jun, D. J. Lee, B. S. Kong, K. W. Paik and S. Jeon, Adv. Mater., 2013, 25, 732-737.

81 Y. Zhang, Y. Wang, J. Yu, L. Chen, J. Zhu and Z. Hu, Polymer, 2014, 55, 4990-5000.

82 P. Pokharel, Q. T. Truong and D. S. Lee, Composites, Part B, 2014, 64, 187-193.

83 S. Lu, S. Li, J. Yu, Z. Yuan and B. Qi, RSC Adv., 2013, 3, 8915. 84 S. G. Prolongo, A. Jiménez-Suárez, R. Moriche and A. Ureña, Eur. Polym. J., 2014, 53, 292-301.

85 M. Martin-Gallego, M. M. Bernal, M. Hernandez, R. Verdejo and M. A. Lopez-Manchado, Eur. Polym. J., 2013, 49, 13471353.

86 S. A. Sydlik, J. Polym. Sci., Part B: Polym. Phys., 2013, 51, 9971006.

87 S. C. Kim, H. I. Lee, H. M. Jeong, B. K. Kim, J. H. Kim and C. M. Shin, Macromol. Res., 2010, 18, 1125-1128.

88 M. C. Hsiao, C. C. Ma, J. C. Chiang, K. K. Ho, T. Y. Chou, X. Xie, C. H. Tsai, L. H. Chang and C. K. Hsieh, Nanoscale, 2013, 5, 5863-5871.

89 V. Mittal, Macromol. Mater. Eng., 2014, 299, 906-931.

90 S. Chatterjee, J. W. Wang, W. S. Kuo, N. H. Tai, C. Salzmann, W. L. Li, R. Hollertz, F. A. Nüesch and B. T. T. Chu, Chem. Phys. Lett., 2012, 531, 6-10.

91 Y. Guo, C. Bao, L. Song, B. Yuan and Y. Hu, Ind. Eng. Chem. Res., 2011, 50, 7772-7783.

92 S. Ganguli, A. K. Roy and D. P. Anderson, Carbon, 2008, 46, 806-817.

93 Z. Chen, X. J. Dai, K. Magniez, P. R. Lamb, B. L. Fox and X. Wang, Composites, Part A, 2014, 56, 172-180.

94 W. Li, A. Dichiara and J. Bai, Compos. Sci. Technol., 2013, 74, 221-227.

95 T. Kuilla, S. Bhadra, D. Yao, N. H. Kim, S. Bose and J. H. Lee, Prog. Polym. Sci., 2010, 35, 1350-1375.

96 M. A. Rafiee, J. Rafiee, Z. Wang, H. Song, Z.-Z. Yu and N. Koratkar, ACS Nano, 2009, 3, 3884-3890. 
97 M. Fang, Z. Zhang, J. Li, H. Zhang, H. Lu and Y. Yang, J. Mater. Chem., 2010, 20, 9635.

98 L. C. Tang, Y. J. Wan, D. Yan, Y. B. Pei, L. Zhao, Y. B. Li, L. B. Wu, J. X. Jiang and G. Q. Lai, Carbon, 2013, 60, 16-27.

99 T. Jiang, T. Kuila, N. H. Kim and J. H. Lee, J. Mater. Chem. A, 2014, 2, 10557.

100 L. Z. Guan, Y. J. Wan, L. X. Gong, D. Yan, L. C. Tang, L. B. Wu, J. X. Jiang and G. Q. Lai, J. Mater. Chem. A, 2014, 2, 15058.

101 I. Zaman, B. Manshoor, A. Khalid, Q. Meng and S. Araby, J. Mater. Sci., 2014, 49, 5856-5865.

102 Q. Meng, J. Jin, R. Wang, H. C. Kuan, J. Ma, N. Kawashima, A. Michelmore, S. Zhu and C. H. Wang, Nanotechnology, 2014, 25, 125707.

103 Y. J. Wan, L. X. Gong, L. C. Tang, L. B. Wu and J. X. Jiang, Composites, Part A, 2014, 64, 79-89.

104 A. B. Nair, B. T. Abraham, P. M. S. Beegum and E. T. Thachil, Polymer, 2014, 55, 3614-3627.

105 Y. J. Wan, L. C. Tang, L. X. Gong, D. Yan, Y. B. Li, L. B. Wu, J. X. Jiang and G. Q. Lai, Carbon, 2014, 69, 467-480.

106 T. Liu, Z. Zhao, W. W. Tjiu, J. Lv and C. Wei, J. Appl. Polym. Sci., 2014, 131, 40236.

107 G. Yu and P. Wu, Polym. Chem., 2014, 5, 96.

108 C. E. Corcione, F. Freuli and A. Maffezzoli, Polym. Eng. Sci., 2013, 53, 531-539.

109 Z. Li, R. J. Young, R. Wang, F. Yang, L. Hao, W. Jiao and W. Liu, Polymer, 2013, 54, 5821-5829.

110 A. S. Wajid, H. S. T. Ahmed, S. Das, F. Irin, A. F. Jankowski and M. J. Green, Macromol. Mater. Eng., 2013, 298, 339-347.

111 H. Feng, X. Wang and D. Wu, Ind. Eng. Chem. Res., 2013, 52, 10160-10171.

112 X. Wang, J. Jin and M. Song, Carbon, 2013, 65, 324-333.

113 L. Cao, X. Liu, H. Na, Y. Wu, W. Zheng and J. Zhu, J. Mater. Chem. A, 2013, 1, 5081.

114 N. Yousefi, X. Lin, Q. Zheng, X. Shen, J. R. Pothnis, J. Jia, E. Zussman and J. K. Kim, Carbon, 2013, 59, 406-417.

115 Z. Li, R. Wang, R. J. Young, L. Deng, F. Yang, L. Hao, W. Jiao and W. Liu, Polymer, 2013, 54, 6437-6446.

116 Y. Yang, W. Rigdon, X. Huang and X. Li, Sci. Rep., 2013, 3, 2086.

117 Y. J. Wan, L. C. Tang, D. Yan, L. Zhao, Y. B. Li, L. B. Wu, J. X. Jiang and G. Q. Lai, Compos. Sci. Technol., 2013, 82, 60-68.

118 I. Zaman, H. C. Kuan, Q. Meng, A. Michelmore, N. Kawashima, T. Pitt, L. Zhang, S. Gouda, L. Luong and J. Ma, Adv. Funct. Mater., 2012, 22, 2735-2743.

119 D. R. Bortz, E. G. Heras and I. Martin-Gullon, Macromolecules, 2012, 45, 238-245.

120 W. Liu, K. L. Koh, J. Lu, L. Yang, S. Phua, J. Kong, Z. Chen and X. Lu, J. Mater. Chem., 2012, 22, 18395.

121 X. Huang, C. Zhi and P. Jiang, J. Phys. Chem. C, 2012, 116, 23812-23820.

122 I. Zaman, T. T. Phan, H. C. Kuan, Q. Meng, L. T. Bao La, L. Luong, O. Youssf and J. Ma, Polymer, 2011, 52, 16031611.

123 K. S. Kim, I. Y. Jeon, S. N. Ahn, Y. D. Kwon and J. B. Baek, J. Mater. Chem., 2011, 21, 7337.
124 J. Liang, Y. Wang, Y. Huang, Y. Ma, Z. Liu, J. Cai, C. Zhang, H. Gao and Y. Chen, Carbon, 2009, 47, 922-925.

125 H. Im and J. Kim, Carbon, 2012, 50, 5429-5440.

126 Q. Li, Y. Guo, W. Li, S. Qiu, C. Zhu, X. Wei, M. Chen, C. Liu, S. Liao, Y. Gong, A. K. Mishra and L. Liu, Chem. Mater., 2014, 26, 4459-4465.

127 J. Jia, X. Sun, X. Lin, X. Shen, Y. W. Mai and J. K. Kim, ACS Nano, 2014, 8, 5774-5783.

128 M. Martin-Gallego, R. Verdejo, M. A. Lopez-Manchado and M. Sangermano, Polymer, 2011, 52, 4664-4669.

129 M. Sangermano, P. Calza and M. A. Lopez-Manchado, J. Mater. Sci., 2013, 48, 5204-5208.

130 L. Yu, J. S. Park, Y. S. Lim, C. S. Lee, K. Shin, H. J. Moon, C. M. Yang, Y. S. Lee and J. H. Han, Nanotechnology, 2013, 24, 155604.

131 C. H. Hsu, M. H. Hsu, K. C. Chang, M. C. Lai, P. J. Liu, T. L. Chuang, J. M. Yeh and W. R. Liu, Polym. Int., 2014, 63, 1765-1770.

132 S. Sarkar and P. K. Das, Rev. Adv. Mater. Sci., 2014, 37, 5382.

133 H. Kim, Y. Miura and C. W. Macosko, Chem. Mater., 2010, 22, 3441-3450.

134 J. R. Potts, D. R. Dreyer, C. W. Bielawski and R. S. Ruoff, Polymer, 2011, 52, 5-25.

135 C. C. Teng, C. C. M. Ma, C. H. Lu, S. Y. Yang, S. H. Lee, M. C. Hsiao, M. Y. Yen, K. C. Chiou and T. M. Lee, Carbon, 2011, 49, 5107-5116.

136 M. Naebe, J. Wang, A. Amini, H. Khayyam, N. Hameed, L. H. Li, Y. Chen and B. Fox, Sci. Rep., 2014, 4, 4375.

137 X. Wang, W. Xing, P. Zhang, L. Song, H. Yang and Y. Hu, Compos. Sci. Technol., 2012, 72, 737-743.

138 N. Savage, Nature, 2012, 483, 30-31.

139 L. Ramos-Galicia, L. N. Mendez, A. L. Martínez-Hernández, A. Espindola-Gonzalez, I. R. Galindo-Esquivel, R. FuentesRamirez and C. Velasco-Santos, Int. J. Polym. Sci., 2013, 2013, 1-7.

140 D. Wang, K. Zhou, W. Yang, W. Xing, Y. Hu and X. Gong, Ind. Eng. Chem. Res., 2013, 52, 17882-17890.

141 B. Qi, eXPRESS Polym. Lett., 2014, 8, 467-479.

142 Q. Liu, X. Zhou, X. Fan, C. Zhu, X. Yao and Z. Liu, Polym.Plast. Technol. Eng., 2012, 51, 251-256.

143 S. Bai and X. Shen, RSC Adv., 2012, 2, 64.

144 S. Chandrasekaran, N. Sato, F. Tölle, R. Mülhaupt, B. Fiedler and K. Schulte, Compos. Sci. Technol., 2014, 97, 90-99.

145 W. Yu, J. Fu, X. Dong, L. Chen and L. Shi, Compos. Sci. Technol., 2014, 92, 112-119.

146 H. Bai, C. Li and G. Shi, Adv. Mater., 2011, 23, 1089-1115. 147 D. R. Cooper, B. D'Anjou, N. Ghattamaneni, B. Harack, M. Hilke, A. Horth, N. Majlis, M. Massicotte, L. Vandsburger, E. Whiteway and V. Yu, ISRN Condens. Matter Phys., 2012, 2012, 1-56.

148 J. K. W. Sandler, J. E. Kirk, I. A. Kinloch, M. S. P. Shaffer and A. H. Windle, Polymer, 2003, 44, 5893-5899.

149 M. Monti, M. Rallini, D. Puglia, L. Peponi, L. Torre and J. M. Kenny, Composites, Part A, 2013, 46, 166-172. 
150 S. T. Huxtable, D. G. Cahill, S. Shenogin, L. Xue, R. Ozisik and P. Keblinski, Nat. Mater., 2003, 2, 731-734.

151 L. M. Veca, M. J. Meziani, W. Wang, X. Wang, F. Lu, P. Zhang, Y. Lin, R. Fee, J. W. Connell and Y. P. Sun, Adv. Mater., 2009, 21, 2088-2092.

152 G. Pollack, Rev. Mod. Phys., 1969, 41, 48-81.

153 M. Martin-Gallego, R. Verdejo, M. Khayet, J. M. O. D. Zarate, M. Essalhi and M. A. Lopez-Manchado, Nanoscale Res. Lett., 2011, 6, 610-616.

154 S. Wang, M. Tambraparni, J. Qiu, J. Tipton and D. Dean, Macromolecules, 2009, 42, 5251-5255.

155 A. Yu, P. Ramesh, M. E. Itkis, E. Bekyarova and R. C. Haddon, J. Phys. Chem. C, 2007, 111, 7565-7569.

156 F. Ren, G. Zhu, P. Ren, Y. Wang and X. Cui, Appl. Surf. Sci., 2014, 316, 549-557.

157 S. Liu, H. Yan, Z. Fang and H. Wang, Compos. Sci. Technol., 2014, 90, 40-47.

158 M. Y. Shen, C. F. Kuan, H. C. Kuan, C. H. Chen, J. H. Wang, M. C. Yip and C. L. Chiang, J. Nanomater., 2013, 2013, 1-10.

159 S. Y. Yang, W. N. Lin, Y. L. Huang, H. W. Tien, J. Y. Wang, C. C. M. Ma, S. M. Li and Y. S. Wang, Carbon, 2011, 49, 793803.

160 H. Kim, A. A. Abdala and C. W. Macosko, Macromolecules, 2010, 43, 6515-6530.

161 R. Kotsilkova and P. Pissis, Thermoset Nanocomposites for Engineering Applications, 2007.

162 L. Chen, S. Chai, K. Liu, N. Ning, J. Gao, Q. Liu, F. Chen and Q. Fu, ACS Appl. Mater. Interfaces, 2012, 4, 4398-4404.

163 J. K. Park and D. S. Kim, Polym. Eng. Sci., 2014, 54, 969-976.

164 D. Galpaya, M. Wang, G. George, N. Motta, E. Waclawik and C. Yan, J. Appl. Phys., 2014, 116, 053518.

165 N. Saurín, J. Sanes and M. D. Bermúdez, Tribol. Lett., 2014, 56, 133-142.

166 F. Liu and K. Guo, Polym. Adv. Technol., 2014, 25, 418-423.

167 K. Liu, S. Chen, Y. Luo, D. Jia, H. Gao, G. Hu and L. Liu, Compos. Sci. Technol., 2013, 88, 84-91.

168 X. Zhang, O. Alloul, Q. He, J. Zhu, M. J. Verde, Y. Li, S. Wei and Z. Guo, Polymer, 2013, 54, 3594-3604.

169 S. G. Prolongo, A. Jimenez-Suarez, R. Moriche and A. Ureña, Compos. Sci. Technol., 2013, 86, 185-191.

170 Z. Wang, P. Wei, Y. Qian and J. Liu, Composites, Part B, 2014, 60, 341-349.

171 X. Wang, L. Song, W. Pornwannchai, Y. Hu and B. Kandola, Composites, Part A, 2013, 53, 88-96.

172 G. Huang, S. Chen, S. Tang and J. Gao, Mater. Chem. Phys., 2012, 135, 938-947.
173 C. P. Sarkos, Technical Papers of the Annual Technical Conference, 1996, vol. 54, pp. 3068-3071.

174 S. Pack, Flame Retard., 2015, 115-130.

175 X. Wang, L. Song, H. Yang, W. Xing, B. Kandola and Y. Hu, J. Mater. Chem., 2012, 22, 22037.

176 Z. Wang, X. Z. Tang, Z. Z. Yu, P. Guo, H. H. Song and X. S. Duc, Chin. J. Polym. Sci., 2011, 29, 368-376.

177 X. Qian, L. Song, B. Yu, B. Wang, B. Yuan, Y. Shi, Y. Hu and R. K. K. Yuen, J. Mater. Chem. A, 2013, 1, 6822-6830.

178 G. Huang, J. Gao, X. Wang, H. Liang and C. Ge, Mater. Lett., 2013, 66, 187-189.

179 K. Y. Li, C. F. Kuan, H. C. Kuan, C. H. Chen, M. Y. Shen, J. M. Yang and C. L. Chiang, Mater. Chem. Phys., 2014, 146, 354-362.

180 S. D. Jiang, Z. M. Bai, G. Tang, Y. Hu and L. Song, Ind. Eng. Chem. Res., 2014, 53, 6708-6717.

181 X. Wang, S. Zhou, W. Xing, B. Yu, X. Feng, L. Song and Y. Hu, J. Mater. Chem. A, 2013, 1, 4383.

182 D. Zhuo, R. Wang, L. Wu, Y. Guo, L. Ma, Z. Weng and J. Qi, J. Nanomater., 2013, 2013, 1-7.

183 F. Inam, D. Y. Wong, M. Kuwata and T. Peijs, J. Nanomater., 2010, 2010, 453420.

184 S. Chatterjee, F. Nafezarefi, N. H. Tai, L. Schlagenhauf, F. A. Nüesch and B. T. T. Chu, Carbon, 2012, 50, 5380-5386.

185 S. Kumar, L. L. Sun, S. Caceres, B. Li, W. Wood, A. Perugini, R. G. Maguire and W. H. Zhong, Nanotechnology, 2010, 21, 1-9.

186 A. Yu, P. Ramesh, X. Sun, E. Bekyarova, M. E. Itkis and R. C. Haddon, Adv. Mater., 2008, 20, 4740-4744.

187 K. E. Prasad, B. Das, U. Maitra, U. Ramamurty and C. N. R. Rao, Proc. Natl. Acad. Sci. U. S. A., 2009, 106, 13186-13189.

188 L. Yue, G. Pircheraghi, S. A. Monemian and I. ManasZloczower, Carbon, 2014, 78, 268-278.

189 K. Sethuraman, P. Prabunathan and M. Alagar, RSC Adv., 2014, 4, 30485.

190 Z. A. Ghaleb, M. Mariatti and Z. M. Ariff, Composites, Part A, 2014, 58, 77-83.

191 L. Chen, H. Jin, Z. Xu, M. Shan, X. Tian, C. Yang, Z. Wang and B. Cheng, Mater. Chem. Phys., 2014, 145, 186-196.

192 O. Starkova, S. Chandrasekaran, L. A. S. A. Prado, F. Tölle, R. Mülhaupt and K. Schulte, Polym. Degrad. Stab., 2013, 98, 519-526.

193 Y. Li, R. Umer, A. Isakovic, Y. A. Samad, L. Zheng and K. Liao, RSC Adv., 2013, 3, 8849. 